\title{
Warm Ischemia Procedure
}

National Cancer Institute

\section{Source}

National Cancer Institute. Warm Ischemia Procedure. NCI Thesaurus. Code C116557.

A surgical procedure during which the blood supply to an org an or tissue is interrupted and then later reestablished, while maintaining the organ at physiologic body temperature. 